\title{
Rheumatoid Arthritis Saudi Database (RASD): Disease Characteristics and Remission Rates in a Tertiary Care Center
}

This article was published in the following Dove Press journal: Open Access Rheumatology: Research and Reviews

Hani Almoallim ${ }^{1-3}$
Rola Hassan
Mohamed Cheikh ${ }^{2,3}$
Hanan Faruqui ${ }^{2}$
Reem Alquraa ${ }^{2}$
Ayman Eissa
Aous Alhazmi
Roaa Alsolaimani ${ }^{2,4}$
Nahed Janoudi

'Department of Medicine, Faculty of
Medicine, Umm Alqura University,
Makkah, Saudi Arabia; ${ }^{2}$ Internal Medicine
Department, Doctor Soliman Fakeeh
Hospital, Jeddah, Saudi Arabia; ${ }^{3}$ Alzaidi
Chair of Research in Rheumatic Diseases,
Umm Alqura University, Makkah, Saudi
Arabia; ${ }^{4}$ Department of Medicine, Faculty
of Medicine, King Abdulaziz University,
Jeddah, Saudi Arabia

Jeddah, Saudi Arabia
Correspondence: Rola Hassan;

Hani Almoallim

Email r.toufiq@hotmail.com;

hanialmoallim@gmail.com
Background: National Registries are essential to direct current practice. Rheumatoid arthritis (RA) registries in the middle east and North Africa remain scarcely represented.

Objective: To describe a population of Saudi RA patients and to compare the findings to internationally reported data.

Methods: This is an observational study that was conducted at Doctor Soliman Fakeeh Hospital (DSFH) in Saudi Arabia. The study ran from 2014 to 2018 using a pool of 433 patients. Inclusion criteria included adults older than 18 years of age who fulfilled the 2010 American College of Rheumatology criteria for the diagnosis of RA and who were also regular visitors in our rheumatology clinics. Data were collected directly from patients and entered in a specially designed program.

Results: At initial presentation, $45.5 \%$ had demonstrated active disease (moderate or high disease activity) based on DAS-28-CRP scores, while $54.5 \%$ were in low disease activity or remission. The remission rates after 1 year had increased to $79.6 \%$ (345 patients), while $9.7 \%$ (42 patients) and 10.6\% (46 patients) had low disease activity and moderate disease activity, respectively. It was also found that the female gender, higher Health Assessment Questionnaire-Disability Index (HAQ-DI) and longer lag1/lag2 periods were associated with higher disease activity in our population.

Conclusion: We detected higher remission rates at 1 year of follow-up. This could be attributed to many factors, including good referral systems with easier access to biologics. We aim to expand this registry to the national level.

Keywords: rheumatoid arthritis, disease-modifying antirheumatic drugs, biologics, TNF blockers, registry, remission rates

\section{Introduction}

Rheumatoid arthritis (RA) is a chronic progressive inflammatory disease that causes irreversible joint deformities. This can have debilitating effects on a patient's overall wellbeing. RA has a global prevalence rate of $0.5-1.1 \%$ with an annual incidence rate of 20-50 cases per 100000 of the American and North European population. ${ }^{1}$

One of the greatest impediments to health care access is the perceived lag times from the start of the patient's complaint until the final diagnosis and provision of appropriate medications. Lag 1 and Lag 2 describe the period between the patient's symptoms to referral to a rheumatologist while Lag 3 and Lag 4 pick up from that visit to the initiation of medical therapy. Lag periods were studied and reported in a recent international systematic review at 3.4, 2.13, 2.91 and 2.14 months for Lag 1, Lag 2, Lag 
3 and Lag 4, respectively. ${ }^{2}$ In Saudi Arabia, lag periods seemed to fall behind global standards by a wide margin, at 6.2 months for Lag1, while the total time from onset of symptoms to RA diagnosis was calculated at 30 months. ${ }^{3}$

Early diagnosis was found to halt the ailment's relentless progression to joint destruction which carried a detrimental effect on the patient's functional and psychological state. A study found that only $31 \%$ of RA patients visited a rheumatologist within less than 12 weeks of symptom onset, those who did had ameliorated progression rates at 6 years as measured by the Sharp/van der Heijde score (SHS) as well as higher rates of DMARD-free remission than patients who delayed their presentation to more than 12 weeks. $^{4}$

Registries are widely mentioned in literature as a method that studied a given population in a way that is more applicable to clinical practice. ${ }^{5}$ Although there are numerous registries that previously set place in Europe and north America, the middle east and Africa remain scarcely studied with a few published small-scaled hospital reports. ${ }^{3}$ Registries are imperative to study a disease's unique course in a given population, which may or may not align with its counterparts in western populations. Therefore, we established a Saudi registry for rheumatoid arthritis called Rheumatoid Arthritis Saudi Database (RASD). Future plans are to recruit other centers and patients inside Saudi Arabia and to RASD.

The main objectives of this study were to describe the population of rheumatoid arthritis patients in a single center in Saudi Arabia using different variables and to compare these findings to internationally reported data. This comparison may help to extrapolate differences in disease presentation, treatment and also feasibility of access to care, which in turn could provide vital input on areas of improvement to better health care provision.

\section{Methodology}

This is an observational, analytical study that was conducted at Doctor Soliman Fakeeh Hospital (DSFH), which is a private, tertiary hospital in Saudi Arabia's western region. DSFH employs three full and half time rheumatology consultants covering daily clinics. The study ran from December of 2014 to December of 2018 using a pool of 433 patients. Inclusion criteria included adults older than 18 years of age who fulfilled the 2010 American College of Rheumatology criteria for the diagnosis of RA and who were also regular visitors in our rheumatology clinics. Irregular visitors or patients who have lost follow up (142 patients) were excluded from this study.
Ethical approval was obtained from the Institutional Review Board (IRB) in DSFH.

Data were collected directly from patients and entered in a specially designed program for this registry. All remaining required data for the registry was obtained from the hospital's electronic database. The data were used to tabulate the main demographic features (age, sex, etc.). Time of symptom onset was also recorded, as well as the lag period to the first encounter with a health care provider (lag 1) and the time from the initial consult to the final diagnosis (lag 2, which represents the sum of lag 2 and lag 3 as defined in the previous work). ${ }^{2}$ Patients who were diagnosed prior to visiting DSFH were included as well in lag time calculations. Additionally, the specialty of the diagnosing physician was mentioned as well as the first presenting symptom. Results of autoantibodies including rheumatoid factor (RF), anti-cyclic citrullinated peptide (ACPA) and anti-nuclear antibodies (ANA) were added.

Following this, a review of the patients' medications was done, including whether they were receiving conventional synthetic disease-modifying anti-rheumatic drugs (cs-DMARD), a biologic (b-DMARD) or targeted synthetic (ts-DMARD). Disease Activity Score-28-C reactive protein (DAS-28-CRP) was calculated on presentation and on subsequent visits with intervals ranging from 3 to 6 months between them. Finally, disability was measured by Health Assessment Questionnaire-Disability Index (HAQ-DI).

Descriptive statistics were presented as numbers and percentages for qualities variables, whereas mean \pm standard deviation (SD) was presented for quantities variables. Multiple regression analyses were assessed to identify factors associated with DAS-28. The test was two-tailed and $\mathrm{p}<0.05$ was considered statistically significant. Statistical analyses were performed by SPSS software Statistics 23 (SPSS Inc., IBM, Chicago, USA).

\section{Results}

In the period of December 2014 to December 2018, a total of 433 patients were included in this study. Out of these patients, 109 were males, a group comprising $25.2 \%$ of subjects sampled and 324 were females, a group comprising $74.8 \%$ of subjects sampled with a ratio of $1: 3$. Of this population, the mean age was found to be $49.3 \pm 11$ years. Patients demographics including serological markers are plotted in Table 1. Analysis of presenting symptoms showed that 217 patients $(50.1 \%)$ had complained of joint pain, whilst 116 patients $(26.8 \%)$ had both pain and stiffness, and $100(23.1 \%)$ patients had a combination of joint pain, stiffness and swelling. 
Table I Baseline Demographics and Characteristics for 433 Rheumatoid Arthritis Patients

\begin{tabular}{|c|c|c|}
\hline & & N (\%) \\
\hline \multirow[t]{2}{*}{ Gender } & Male & $109(25.2)$ \\
\hline & Female & $324(74.8)$ \\
\hline \multirow[t]{8}{*}{ Comorbidities } & Osteoporosis & $117(27.1)$ \\
\hline & Thyroid dysfunction & $109(25.3)$ \\
\hline & Dyslipidemia & $98(22.7)$ \\
\hline & Hypertension & $91(21.7)$ \\
\hline & Diabetes Mellitus & $89(18.6)$ \\
\hline & Asthma & $6 I(14)$ \\
\hline & Allergy & $22(5)$ \\
\hline & Cancer & $3(0.6)$ \\
\hline \multirow[t]{2}{*}{ Smoking } & Yes & 149 (34.4) \\
\hline & No & $284(65.5)$ \\
\hline \multirow[t]{4}{*}{ Serology } & RF & $246(56.8)$ \\
\hline & ACPA & $265(61.2)$ \\
\hline & RF and ACPA & $201(46.4)$ \\
\hline & ANA & $163(37.5)$ \\
\hline \multirow{4}{*}{$\begin{array}{l}\text { HAQ } \\
\text { (Lower score = Less } \\
\text { disability) }\end{array}$} & 0 to 0.5 (less & $204(47.1)$ \\
\hline & disabled) & \\
\hline & 0.5 to I (Moderate) & $126(29.1)$ \\
\hline & >I (more disabled) & $103(23.8)$ \\
\hline
\end{tabular}

Abbreviations: ACPA, anti-cyclic citrullinated peptide antibody; ANA, antinuclear antibodies; HAQ, Health Assessment Questionnaire; RF, rheumatoid factor.

Time from the start of symptoms to visiting a medical professional was studied (Lag 1) and showed a mean \pm standard deviation (SD) of $4.7 \pm 5.3$ months. Moreover, the mean $\pm \mathrm{SD}$ of duration from the aforementioned consultation to definitive RA diagnosis ( $\mathrm{Lag} 2$ ) was $8.9 \pm 12.6$ months (Table 2).

Further analysis of data revealed that nearly 211 patients (48.7\%) had chosen orthopedic surgeons for their initial visits, while 157 (36.3\%) were evaluated by rheumatologists. Internal medicine physicians were consulted by 53 patients (12.2\%) and other specialties were visited by 12 patients (2.8\%). The diagnosis of RA was established by rheumatologists in 278 patients $(64.2 \%)$ and by orthopedic surgeons in
87 patients $(20 \%)$. Internal medicine physicians and other specialties were responsible for diagnosing 40 patients $(9.3 \%)$ and 28 patients $(6.5 \%)$, respectively.

Patients who received csDMARD were 304 patients $(70.2 \%)$ while 54 patients $(12.5 \%)$ received anti-tumor necrosis factor (anti TNF) biological drugs, and 75 patients $(17.3 \%)$ were given non-anti TNF DMARDs. Among these patients, 34 patients $(26.3 \%)$ received Tofacitinib and 30 patients $(23.6 \%)$ used Adalimumab. Etanercept was used in 24 patients (18.7\%) and Tocilizumab in 20 patients (15.2\%), 11 patients (8.4\%) were treated with Certolizumab and 10 patients $(7.8 \%)$ with Rituximab. No patients received Infliximab nor Abatacept in our study. Figure 1 describes the pharmacological therapies that were given to the patients.

At initial presentation, $45.5 \%$ had demonstrated active disease (moderate or high disease activity) based on DAS28-CRP scores while $54.5 \%$ were in low disease activity or remission. The remission rates after 1 year had increased to 345 patients $(79.6 \%)$, while 42 patients $(9.7 \%)$ and 46 patients $(10.6 \%)$ had low disease activity and moderate disease activity, respectively. No patients sustained high disease activity at the end of follow up. A multiple regression was carried out to investigate whether gender, body mass index, comorbidity, smoking, duration of RA disease, Lag and HAQ could significantly predict DAS-28. The results of the regression indicated that the model explained $8.2 \%$ of the variance and that the model was a significant predictor of DAS-28 score performance, $F(7319)=4.081, p=0.000$. The HAQ score contributed significantly to the model $(\mathrm{B}=0.235$, $\mathrm{p}<0.05$ ). The Lag (lag1 and lag2) was also significant $(\mathrm{B}=0.331, \mathrm{p}<0.05)$. Lastly, gender was statistically significant $(\mathrm{B}=0.383, \mathrm{p}<0.05)$. However, other variables were not (Table 3 ). The final predictive model was:

DAS-28 $=0.770+\left(0.38 *^{*}\right.$ gender $\quad$ (female $)+$ $(0.011 * \mathrm{BMI})+(0.033 *$ Comorbidity $)-(0.093 * \mathrm{SMOKING})-$ $(0.006 *$ Duration $)+(0.331 * \mathrm{LAG})+(0.235 * \mathrm{HAQ})$

Table 2 Descriptive Statistics for Lag I and Lag 2 Continues Variables

\begin{tabular}{|l|l|l|l|l|l|}
\hline & N & Minimum & Maximum & Mean & Standard Deviation \\
\hline Lag I & 433 & 2.00 & 60.00 & 4.7296 & 5.39700 \\
Lag 2 & 433 & 3.00 & 120.00 & 8.9720 & 12.63263 \\
Total (Lag) & 433 & 2.00 & 183.00 & 13.5751 & 14.12427 \\
RA Duration (yr) & 433 & 0.1 & 20 & 6.56 & 5.519 \\
Age (yr) & 433 & 18 & 83 & 49.26 & 11.030 \\
\hline
\end{tabular}

Abbreviations: Lag I, lag period from symptom onset to the first encounter with a health care provider; Lag 2, the time from the initial consult to the final diagnosis; RA, rheumatoid arthritis. 


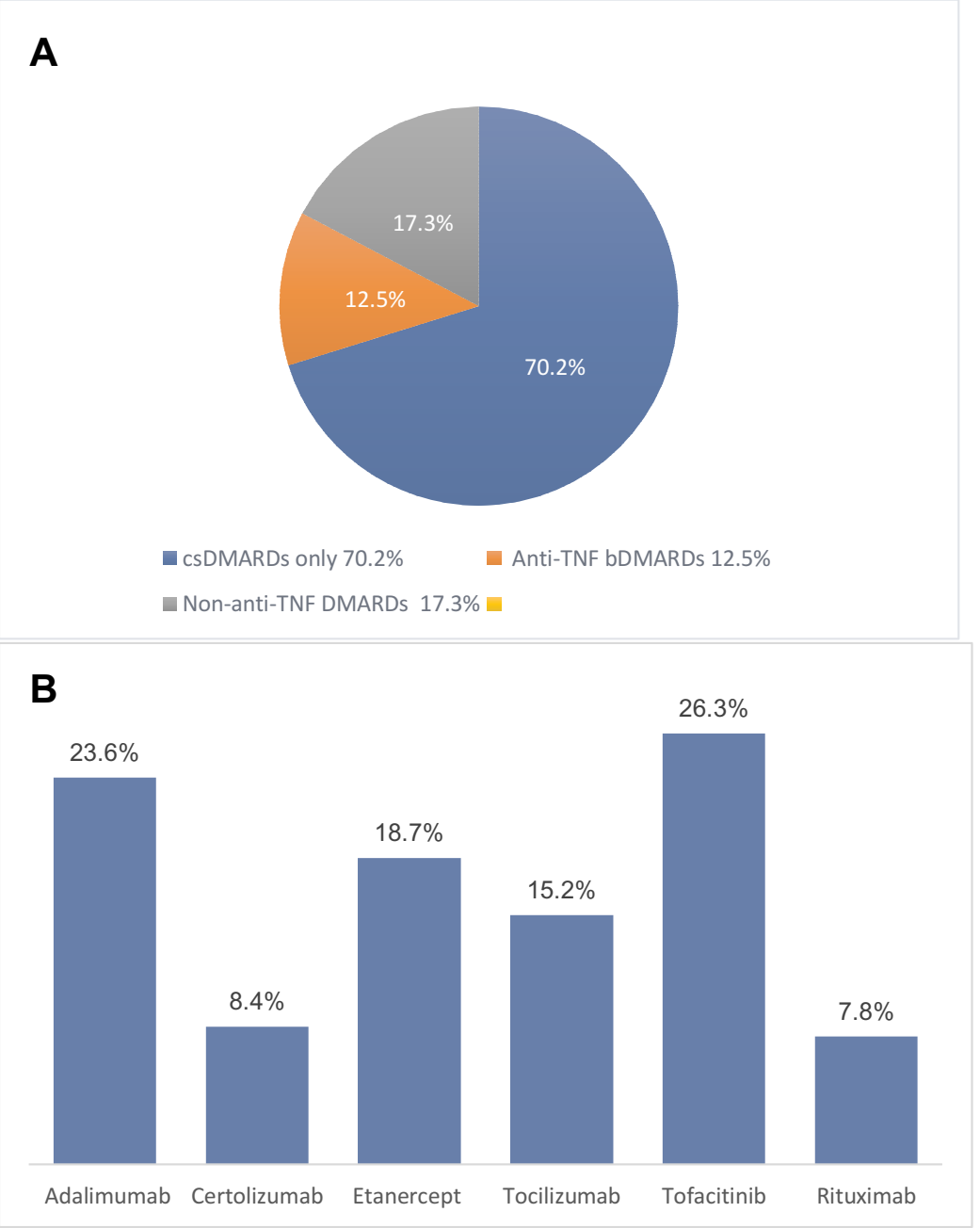

Figure I (A) Shows a pie chart representing the percentage of patients who received Anti-TNF bDMARDs, Non-Anti-TNF DMARDs and those who received only csDMARDs. (B) Provides the percentages of each agent used among both anti-TNF bDMARDs and non-anti-TNF DMARDs.

Abbreviations: Anti-TNF bDMARDs, anti-tumor necrosis factor biologic disease-modifying anti-rheumatic drugs; csDMARDs, conventional synthetic disease-modifying anti-rheumatic drugs; Non-Anti-TNF DMARDs, non-anti-tumor necrosis factor disease-modifying anti-rheumatic drugs.

Lastly, out of our sample size, 18 patients $(4.15 \%)$ were diagnosed with latent tuberculous (TB) with no documented cases of active TB. Malignancy was also found in five patients $(1.15 \%)$, including two patients with breast cancer, one with thyroid cancer, another with colon cancer, these patients were receiving either Methotrexate or Hydroxychloroquine. There was also one incidence with urinary bladder cancer in a patient who received Rituximab for 2 years; however, this patient also had multiple risk factors for malignancy, including smoking and schistosomiasis infection.

\section{Discussion}

Our study was conducted in a single center in Saudi Arabia using a pool of 433 patients. The aim was to describe the population of rheumatoid arthritis and to compare these findings to previously published data registries. In our population, it was found that the mean age of diagnosis was 49.2 years, this is in concordance with the

Table 3 Multiple Regression Model (DAS-28 Dependent)

\begin{tabular}{|l|l|l|l|}
\hline Model & B & t & Sig. \\
\hline (Constant) & 0.770 & 2.297 & 0.022 \\
Lag & 0.331 & 2.975 & 0.037 \\
HAQ & 0.235 & 3.289 & 0.001 \\
Gender & 0.383 & 3.176 & 0.002 \\
BMI & 0.011 & 1.444 & 0.150 \\
Smoking & 0.093 & 0.794 & 0.428 \\
RA Duration & 0.006 & 0.762 & 0.447 \\
Comorbidity & 0.033 & 0.368 & 0.713 \\
\hline
\end{tabular}

Abbreviations: BMI, body mass index; DAS-28, disease activity score 28 ; HAQ, health assessment questionnaire; Lag, period from symptom onset to the final diagnosis; RA, rheumatoid arthritis. 
well-established notion that RA affects middle to older aged individuals. ${ }^{6}$ Female gender represented the vast majority of our population $(74.8 \%$ ) with a male to female ratio of $1: 3$, this agreed with the disease's known predilection. $^{6,7}$ RF and ACPA were positive in $56.8 \%$ and $61.2 \%$ of patients, respectively, resembling numbers reported in similarly conducted studies. ${ }^{8}$ Seropositivity was historically associated with erosive disease and extraarticular manifestations, however, such associations were not reported in our study. ${ }^{9}$

Remission rates based on the DAS 28-CRP reached $79.6 \%$ after 1 year of treatment and follow up, which ranks higher than international studies that have pursued comparable follow-up plans. Darawankul et al ${ }^{10}$ had a remission rate of $14.6 \%$ after 1 year of follow up. Similarly, Mierau et $\mathrm{al}^{11}$ and Barnabe et $\mathrm{al}^{12}$ had reported a $19.6 \%$ and a $37 \%$ remission rate, respectively. However, low disease activity and remission rates were high upon entry to our study, these rates were not only maintained but were also increased by the time the study ended. The main arguments for our high remission rates include earlier detection strategies, as evidence ${ }^{13}$ showed that it is associated with improved outcomes. Good referral systems are another possibility as the hospital that this study was conducted in is a private, insurancebased hospital with more access to specialized physicians; therefore, our results may not be representative of the national healthcare system. One of our aims is to nationalize our registry across Saudi Arabia. Easier access to biologics is another potential cause, and although Saudi Arabia lacks its own national guidelines regarding RA management, we have one of the highest rates of biologics used in the middle east, ${ }^{14}$ making it a good platform to study the effects of biologics in different management approaches. An example would be the use of biologics as temporary induction treatments for RA, this was previously studied by Emery et al (the COMET study). ${ }^{15}$

Lag periods were studied in our research, with the mean of Lag 1 estimated to be 4.72 months while Lag 2 was 8.9 months, these numbers are aligned with studies published from the $\mathrm{UAE}^{16}$ and the European Union. ${ }^{17}$ Longer delays were previously noted locally, ${ }^{3}$ whilst shorter lag periods were outlined in the 2011 Danish and American registries, ${ }^{18,19}$ which recorded a remarkable mean lag1/2 of only 4 months. It is our hope that once our registry expands to other centers we might then be able to have a more accurate estimate of how our lag times have progressed on a nationwide level.

Longer lag1/lag2 periods, the female gender and a higher HAQ-DI score were associated with higher disease activity in our study. The Kuriya Canadian Cohort reported similar results pertaining to gender. ${ }^{20}$ Shorter lag periods were correlated with improved outcomes, as earlier access to conventional or biologic DMARDs leads to better disease control. ${ }^{21}$

In our study, most of our patients had stated that joint pain alone was their initial presenting symptom $(50.1 \%)$, whilst the combinations of pain and stiffness and of pain, swelling and stiffness were found in $26.8 \%$ and $23.1 \%$ of patients, respectively. These latter rates were similar to data previously published in a local study ${ }^{3}$ and also to ones conducted in the United States. ${ }^{19}$ It should be added that such findings could be used to increase the awareness of the infrequency of these symptoms.

There is a misconception about the scope of rheumatology practice in our society as patients believe that joint pains are dealt with by orthopedic surgeons. It was observed that the largest number of patients elected to visit orthopedic surgeons (48.7\%). This predilection was also found in an American study. ${ }^{19}$ Interestingly, an increased preference for visiting rheumatologists was found in our study (36.3\%) compared to an earlier local report. ${ }^{3}$ The current vision is geared towards strengthening of primary care sectors as it was also demonstrated that training these physicians in musculoskeletal examination had improved their accuracy in detecting arthritis. ${ }^{22}$

The majority of our patients $(70.2 \%)$ received csDMARDs, whilst a smaller number received antiTNF and non-anti-TNF DMARDs, at $12.5 \%$ and $17.3 \%$, respectively. The most common non csDMARD used was Tofacitinib (26.3\%), followed by Adalimumab (23.6\%), and Etanercept (18.7\%). Treatment with different non csDMARDs varies widely between centers even in the same country based on availability, routes of administration and cost. A review of many international registries showed differing patterns of use. The DANBIO registry $^{23}$ reported that Infliximab (49\%) was their most given, followed by Adalimumab (29\%) and Etanercept $(22 \%)$. Similarly, data from a Swedish registry ${ }^{24}$ noted that they used Infliximab in $54 \%$ of their patients, followed by Etanercept (34\%) and Adalimumab (12\%). Finally, French registries ${ }^{25}$ preferred Etanercept (51\%) and Infliximab (31\%). 
Many studies demonstrated the increased risk of TB reactivation especially among those treated with anti-TNF agents. $^{26,27}$ A United Kingdom cohort ${ }^{28}$ reported that patients on Infliximab had accelerated rates of reactivation compared to Etanercept and Adalimumab, however, our study did not include any patients on Infliximab. Tofacitinib was also singled out with causing higher risks of reactivation in another report. ${ }^{29} \mathrm{~A}$ reason behind our lack of TB reactivation could be attributed to the relatively younger age and fewer comorbidities in our participants. Few studies have addressed this risk in TB endemic regions, ${ }^{30,31}$ this is also highlighted by the absence of local guidelines in patients who are receiving biologics. However, we did follow a strict system of screening and treatment of latent TB in consultation with an infectious disease specialist.

There is an increased risk of lymphoma that is associated with RA, ${ }^{32,33}$ studies vary regarding the risk with the additional use of biologics, ${ }^{34,35}$ however, we have not reported any such incidents. With regard to solid malignancies, it was found that males who suffer from RA had higher rates of lung, liver and esophageal cancer while females had surprisingly lower incidence rates of breast, ovary, uterus, cervical cancer as well as melanoma. ${ }^{36}$ Our data differed as we reported the incidence of five solid malignancies, including breast, thyroid, colon and bladder cancer. It is difficult to correlate these malignancies with the disease or the interventions given, as other risk factors were present. Longer term follow-up is needed for a definitive conclusion.

We acknowledge several limitations in our study, as data presented may not reflect nationwide disease trends. Suboptimal recording of medication minor and major side effects is another limiting factor as patients may initially be treated in other centers. High dropout rates are not an unusual phenomenon in data registries.

The outcome of this registry may give feedback to advance clinical care policies. High remission rates can be achieved in our society with good referral systems and easier access to biologics.

\section{Ethics and Consent}

Informed consent was taken from all the patients that participated. This study was conducted in accordance with the declaration of Helsinki.

\section{Disclosure}

This study was funded by the Alzaidi Chair of Research in Rheumatic Diseases, Umm Alqura University, Makkah,
Saudi Arabia. Rheumatoid arthritis Saudi Database (RASD) is a registry designed and funded by the Alzaidi Chair of Research in Rheumatic Diseases and partially funded by Pfizer pharmaceuticals. Hani Almoallim reports grants and non-financial support from Alzaidi Chair of Research in Rheumatic Diseases, and grants from Pfizer Pharmaceutical, during the conduct of the study. The authors report no other potential conflicts of interest for this work.

\section{References}

1. Alamanos Y, Drosos AA. Epidemiology of adult rheumatoid arthritis. Autoimmun Rev. 2005;4(3):130-136. doi:doi:10.1016/j.autrev.2004. 09.002 .

2. Barhamain AS, Magliah RF, Shaheen MH, et al. The journey of rheumatoid arthritis patients: a review of reported lag times from the onset of symptoms. Open Access Rheumatol. 2017;9:139-150. doi:doi:10.2147/OARRR.S138830.

3. Hussain W, Noorwali A, Janoudi N, et al. From symptoms to diagnosis: an observational study of the journey of rheumatoid arthritis patients in Saudi Arabia. Oman Med J. 2016;31(1):29-34. doi: doi:10.5001/omj.2016.06.

4. van der Linden MP, le Cessie S, Raza K, et al. Long-term impact of delay in assessment of patients with early arthritis. Arthritis Rheum. 2010;62(12):3537-3546. doi:doi:10.1002/art.27692.

5. Saag KG, Teng GG, Patkar NM, et al. American college of rheumatology 2008 recommendations for the use of nonbiologic and biologic disease-modifying antirheumatic drugs in rheumatoid arthritis. Arthritis Rheum. 2008;59(6):762-784. doi:doi:10.1002/art.23721.

6. Myasoedova E, Crowson CS, Kremers HM, Therneau TM, Gabriel SE. Is the incidence of rheumatoid arthritis rising? Results from Olmsted County, Minnesota, 1955-2007. Arthritis Rheum. 2010;62(6):1576-1582. doi:doi:10.1002/art.27425.

7. Weyand CM, Schmidt D, Wagner U, Goronzy JJ. The influence of sex on the phenotype of rheumatoid arthritis. Arthritis Rheum. 1998;41(5):817-822. doi:doi:10.1002/1529-0131(199805)41:5<817:: aid-art7>3.0.CO;2-S.

8. Yu C, Jin S, Wang Y, et al. Remission rate and predictors of remission in patients with rheumatoid arthritis under treat-to-target strategy in real-world studies: a systematic review and meta-analysis. Clin Rheumatol. 2019;38(3):727-738. doi:doi:10.1007/s10067-018-4340-7.

9. Masi AT, Maldonado-Cocco JA, Kaplan SB, Feigenbaum SL, Chandler RW. Prospective study of the early course of rheumatoid arthritis in young adults: comparison of patients with and without rheumatoid factor positivity at entry and identification of variables correlating with outcome. Semin Arthritis Rheum. 1976;4 (4):299-326. doi:doi:10.1016/0049-0172(76)90013-5.

10. Darawankul B, Chaiamnuay S, Pakchotanon R, Asavatanabodee P, Narongroeknawin P. The good EULAR response at the first year is strongly predictive of clinical remission in rheumatoid arthritis: results from the TARAC cohort. Clin Rheumatol. 2015;34(1):43-49. doi:doi:10.1007/s10067-014-2749-1.

11. Mierau M, Schoels M, Gonda G, Fuchs J, Aletaha D, Smolen JS. Assessing remission in clinical practice. Rheumatology (Oxford). 2007;46(6):975-979. doi:doi:10.1093/rheumatology/kem007

12. Barnabe C, Homik J, Barr SG, Martin L, Maksymowych WP. The effect of different remission definitions on identification of predictors of both point and sustained remission in rheumatoid arthritis treated with anti-TNF therapy. $J$ Rheumatol. 2014;41(8):1607-1613. doi: doi:10.3899/jrheum.131451. 
13. Lukas C, Combe B, Ravaud P, Sibilia J, Landew R, van der Heijde D. Favorable effect of very early disease-modifying antirheumatic drug treatment on radiographic progression in early inflammatory arthritis: data from the Étude et Suivi des polyarthrites indifférenciées récentes (study and followup of early undifferentiated polyarthritis). Arthritis Rheum. 2011;63(7):1804-1811. doi:doi:10.1002/art.30371.

14. Dargham SR, Zahirovic S, Hammoudeh M, et al. Correction: epidemiology and treatment patterns of rheumatoid arthritis in a large cohort of Arab patients. PLoS One. 2019;14(3):e0214258. doi: doi:10.1371/journal.pone.0214258.

15. Emery P, Kvien TK, Combe B, et al. Combination etanercept and methotrexate provides better disease control in very early $(\leq 4$ months) versus early rheumatoid arthritis ( $>4$ months and $<2$ years): post hoc analyses from the comet study. Ann Rheum Dis. 2012;71(6):989-992. doi:doi:10.1136/annrheumdis-2011-201066.

16. Zafar S, Badsha H, Mofti A, et al. Efforts to increase public awareness may result in more timely diagnosis of rheumatoid arthritis. J Clin Rheumatol. 2012;18(6):279-282. doi:doi:10.1097/RHU.0b013e31826 76975.

17. Raza K, Stack R, Kumar K, et al. Delays in assessment of patients with rheumatoid arthritis: variations across Europe. Ann Rheum Dis. 2011;70(10):1822-1825. doi:doi:10.1136/ard.2011.151902.

18. Sørensen J, Hetland ML, all departments of rheumatology in Denmark. Diagnostic delay in patients with rheumatoid arthritis, psoriatic arthritis and ankylosing spondylitis: results from the Danish nationwide DANBIO registry. Ann Rheum Dis. 2015;74(3): e12. doi:doi:10.1136/annrheumdis-2013-204867.

19. Raciborski F, Kłak A, Kwiatkowska B, et al. Diagnostic delays in rheumatic diseases with associated arthritis. Reumatologia. 2017;55 (4):169-176. doi:doi:10.5114/reum.2017.69777.

20. Kuriya B, Xiong J, Boire G, et al. Earlier time to remission predicts sustained clinical remission in early rheumatoid arthritis-results from the Canadian early arthritis cohort (CATCH). J Rheumatol. 2014;41 (11):2161-2166. doi:doi:10.3899/jrheum.140137.

21. Raza K, Buckley CE, Salmon M, Buckley CD. Treating very early rheumatoid arthritis. Best Pract Res Clin Rheumatol. 2006;20 (5):849-863. doi:doi:10.1016/j.berh.2006.05.005

22. Almoallim H, Janoudi N, Attar SM, et al. Determining early referral criteria for patients with suspected inflammatory arthritis presenting to primary care physicians: a cross-sectional study. Open Access Rheumatol. 2017;9:81-90. doi:doi:10.2147/OARRR.S134780.

23. Hetland ML, Christensen IJ, Tarp U, et al. Direct comparison of treatment responses, remission rates, and drug adherence in patients with rheumatoid arthritis treated with adalimumab, etanercept, or infliximab: results from eight years of surveillance of clinical practice in the nationwide Danish DANBIO registry. Arthritis Rheum. 2010;62(1):22-32. doi:doi:10.1002/art.27227.

24. Kristensen LE, Kapetanovic MC, Gülfe A, Söderlin M, Saxne T, Geborek P. Predictors of response to anti-TNF therapy according to ACR and EULAR criteria in patients with established RA: results from the South Swedish arthritis treatment group register. Rheumatology (Oxford). 2008;47(4):495-499. doi:doi:10.1093/rheumatology/ken002.
25. Mariette X, Gottenberg JE, Ravaud P, Combe B. Registries in rheumatoid arthritis and autoimmune diseases: data from the French registries. Rheumatology (Oxford). 2011;50(1):222-229. doi:doi:10. 1093/rheumatology/keq368.

26. Wallis RS, Broder MS, Wong JY, Hanson ME, Beenhouwer DO. Granulomatous infectious diseases associated with tumor necrosis factor antagonists. Clin Infect Dis. 2004;38(9):1261-1265. doi: doi: $10.1086 / 383317$.

27. Tubach F, Salmon D, Ravaud P, et al. Risk of tuberculosis is higher with anti-tumor necrosis factor monoclonal antibody therapy than with soluble tumor necrosis factor receptor therapy. Arthritis Rheum. 2009;60(7):1884-1894. doi:doi:10.1002/art.24632.

28. Dixon WG, Hyrich KL, Watson KD, et al. Drug-specific risk of tuberculosis in patients with rheumatoid arthritis treated with anti-TNF therapy: results from the British society for rheumatology biologics register (BSRBR). Ann Rheum Dis. 2010;69(3):522-528. doi:doi:10.1136/ard.2009.118935.

29. Winthrop KL, Park SH, Gul A, et al. Tuberculosis and other opportunistic infections in tofacitinib-treated patients with rheumatoid arthritis. Ann Rheum Dis. 2016;75(6):1133-1138. doi:doi:10.1136/ annrheumdis-2015-207319.

30. Navarra SV, Tang B, Lu L, et al. Risk of tuberculosis with anti-tumor necrosis factor- $\alpha$ therapy: substantially higher number of patients at risk in Asia. Int $J$ Rheum Dis. 2014;17(3):291-298. doi:doi:10.1111/ 1756-185X.12188.

31. Alkadi A, Alduaiji N, Alrehaily A. Risk of tuberculosis reactivation with rituximab therapy. Int J Health Sci (Qassim). 2017;11(2):41-44.

32. Mariette X, Tubach F, Bagheri H, et al. Lymphoma in patients treated with anti-TNF: results of the 3-year prospective French RATIO registry. Ann Rheum Dis. 2010;69(2):400-408. doi:doi:10.1136/ ard.2009.117762.

33. Franklin JP, Symmons DP, Silman AJ. Risk of lymphoma in patients with RA treated with anti-TNFalpha agents. Ann Rheum Dis. 2005;64 (5):657-658. doi:doi:10.1136/ard.2005.035311.

34. Brown SL, Greene MH, Gershon SK, Edwards ET, Braun MM. Tumor necrosis factor antagonist therapy and lymphoma development: twenty-six cases reported to the food and drug administration. Arthritis Rheum. 2002;46(12):3151-3158. doi: doi:10.1002/art.10679.

35. Mercer LK, Galloway JB, Lunt M, et al. Risk of lymphoma in patients exposed to antitumour necrosis factor therapy: results from the British society for rheumatology biologics register for rheumatoid arthritis. Ann Rheum Dis. 2017;76(3):497-503. doi:doi:10.1136/ annrheumdis-2016-209389.

36. Parikh-Patel A, White RH, Allen M, Cress R. Risk of cancer among rheumatoid arthritis patients in California. Cancer Causes Control. 2005;64(5):1001-1010. doi:10.1136/ard.2005.035311
Open Access Rheumatology Research and Reviews is an international, peer-reviewed, open access journal publishing original research, reports, editorials, reviews and commentaries on all aspects of clinical and experimental rheumatology in the clinic and laboratory including the following topics: Pathology, pathophysiology of rheumatological diseases; Investigation, treatment and management of rheumatological diseases; Clinical trials and novel pharmacological approaches for the treatment of rheumatological disorders. The manuscript management system is completely online and includes a very quick and fair peer-review system, which is all easy to use. Visit http://www.dovepress.com/testimonials.php to read real quotes from published authors. 